\title{
Toledo, siglos XII-XV. La coexistencia de cristianos (latinos y mozárabes), musulmanes y judíos. Una síntesis ${ }^{1}$
}

\author{
Toledo, 12th to 15th Centuries. The Coexistence \\ of Christians (Latins and Mozarabs), Muslims and Jews. \\ A Synthesis
}

\author{
Jean-Pierre Molénat \\ CNRS-IRHT, Paris \\ https://orcid.org/0000-0002-8173-9119
}

\begin{abstract}
Durante cuatro siglos, cristianos (de rito romano o visigótico), musulmanes y judíos coexistieron en la ciudad de Toledo. Pero tal coexistencia, antes de terminar de manera trágica, se caracterizó por muchos matices y atravesó circunstancias diversas. Cuando los llamados mozárabes (cristianos arabizados de rito visigótico) se fundieron en la masa cristiana de rito latino y lengua hispánica, después de dominar en la ciudad durante largo tiempo, los musulmanes (mudéjares), nunca muy numerosos, alcanzaron cierto apogeo en el siglo $\mathrm{XIV}$, antes de quedar parcialmente marginalizados en el XV. En cuanto a los judíos, debido al papel que desempeñaban en la gestión del dinero, fueron objeto de la ira y el furor popular, sobre todo en los siglos XIV y XV, incluso después de su conversión, fingida o sincera, a la fe cristiana.
\end{abstract}

Palabras clave: Toledo; mozárabes; cristianos; musulmanes; judíos; coexistencia; judeoconversos.
During four centuries Christians (of Roman and Visigothic rite), Muslims and Jews coexisted in the city of Toledo. But such coexistence, before its tragical end, went through many changes and vicissitudes. While Mozarabs (arabized Christians of Visigothic rite), who had been dominant in the city for a long period of time, mingled with Spanishspeaking and Roman Christians, Muslims (Mudejars), who were always scarce, experienced a climax in the $14^{\text {th }}$ Century, before losing ground and being marginalized in the $15^{\text {th }}$ Century. As regards Jews, their high position in money trade made them the perfect focus for popular disgrace and anger, especially in the $14^{\text {th }}$ and $15^{\text {th }}$ Century, after they converted to Christianism, frankly or in simulated manner.

Key words: Toledo; Mozarabs; Christians; Muslims; Jews; coexistence; conversos.

${ }^{1}$ Versión traducida del francés al español por el autor, agradeciendo a María Jesús Albarrán Martínez las correcciones estilísticas.

Copyright: (C) 2019 CSIC. Este es un artículo de acceso abierto distribuido bajo los términos de la licencia de uso y distribución Creative Commons Reconocimiento 4.0 Internacional (CC BY 4.0). 
A lo largo de los más de cuatro siglos que transcurrieron desde la entrada en la ciudad de los cristianos del norte peninsular (1085) hasta los dos edictos bien conocidos de los Reyes Católicos sobre la expulsión de los judíos (1492) y los musulmanes (1502) de sus reinos de Castilla, Toledo fue testigo de una larga coexistencia de cristianos, divididos entre el rito latino y el de los mozárabes, de musulmanes y judíos.

Es conocido que tan larga coexistencia entre cristianos y fieles de las otras dos religiones abrahámicas acabó de manera trágica, pero este fin fue consecuencia de factores de amplitud superior, presentes en todo el territorio peninsular, en los cuales no vamos a entrar aquí. Para justificar el término "peninsular" bastará con observar la similitud del caso portugués con el de Castilla, el edicto del rey lusitano D. Manuel contra judíos y musulmanes, con fecha de $1497^{2}$ y la masacre de los judíos (conversos) de Lisboa en $1506^{3}$.

\section{Cristianos latinos y mozárabes}

Centrándonos en Toledo, hemos de señalar que el problema de la coexistencia entre las religiones, o los ritos, o más bien sus partidarios, antes de plantearse entre religiones, se planteó entre dos ritos de la misma fe, es decir el cristianismo.

Se sabe que cuando el soberano de León y Castilla, Alfonso VI, entró en Toledo, en mayo de 1085, ya había decidido que sus estados pasasen al rito romano ${ }^{4}$. En consecuencia, se planteó el problema de los cristianos llamados "mozárabes", o sea etimológicamente "arabizados" o "arabizantes", apegados al rito visigótico, que habían mantenido durante el tiempo que fueron sometidos a la dominación musulmana. No solo el soberano encontró en la ciudad del Tajo cierto número de tales "mozárabes", sino que trajo otros de sus expediciones en el sur de la península. Según dice la tradición, se permitió a los mozárabes toledanos la práctica de su rito en parroquias propias, en virtud de la permanencia del culto cristiano en esas iglesias durante la domi-

\footnotetext{
${ }^{2}$ Soyer, The Persecution of the Jews and Muslims of Portugal. Traducción portuguesa, A Perseguição aos Judeus e Muçulmanos de Portugal.

${ }^{3}$ Soyer, "The Massacre of the New Christians of Lisbon".

${ }^{4}$ Fernández Conde, "Política religiosa de Alfonso VI".
} 
nación islámica en la ciudad. Por cierto, no se ha conservado ningún documento que atestigüe tal decisión $\mathrm{real}^{5}$, pero el hecho está corroborado gracias a la existencia de las parroquias, donde se observaba el rito mozárabe-visigótico, en Toledo hasta el siglo $\mathrm{XV}$, en número de seis, frente a las veinte de rito latino. ¿Podemos concluir que los "mozárabes" constituían una minoría en la ciudad después del año1085, como argüía un llorado ilustre medievalista ${ }^{6}$ En primer lugar, tal conclusión está en contradicción con el hecho patente de que la gran mayoría de los documentos toledanos que se conservan de los siglos XII y XIII están redactados en grafía y lengua árabe (todos los documentos que no son de procedencia real o eclesiástica), lo que llevaba al editor y traductor de los 1.200 documentos "mozárabes" de Toledo a pensar que todos los toledanos de los siglos XII y XIII eran "mozárabes", con una evidente dosis de exageración ${ }^{7}$. Consideramos, más bien, que la proporción de seis iglesias mozárabes respecto a la totalidad de la ciudad, refleja la situación anterior al 1085: la de una minoría cristiana "arabizada" en una ciudad mayoritariamente musulmana ${ }^{8}$. Esa minoría, presente cuando la conquista de 1085, se encontró después fortalecida por la venida de cristianos del sur, traídos por Alfonso VI de sus expediciones contra Andalucía, en particular a Guadix, y, a mediados del siglo XII, por la llegada de cristianos andalusíes, que huyeron de la llegada de los almohades". No se puede pensar que tales "nuevos mozárabes" de Toledo se incorporasen a las parroquias de los "mozárabes antiguos" ni que hayan conseguido licencia para seguir con su rito tradicional, pues no se aplicaba para ellos el argumento de la permanencia del culto en sus iglesias durante el período de la dominación islámica. Así se debe entender la bula sin fecha del papa Eugenio III (11451153), dada a petición del arzobispo don Raimundo (1124-1152), que hablaba de un conflicto entre el prelado y gentes "llamadas mozárabes", quienes rehuían obediencia al arzobispo y seguían con su cos-

\footnotetext{
${ }^{5}$ Ramón Gonzálvez Ruiz propone explicar la ausencia de un texto explícito en este asunto por el deseo de Alfonso VI de no enfrentarse con el papa Gregorio VII, creando una tolerancia de hecho, que se convirtió con el tiempo en un derecho adquirido ("Toledo, último reducto del mundo mozárabe", especialmente p. 56.

${ }^{6}$ González, Repoblación de Castilla la Nueva, vol. 2, p. 90.

${ }^{7}$ González Palencia, Los mozárabes de Toledo, vol. preliminar, p. 122.

${ }^{8}$ Molénat, "Y a-t-il eu des mozarabes?"

${ }^{9}$ Molénat, "Sur le rôle des Almohades".
} 
tumbre antigua en lo referente al oficio de la misa y vestidos clericales, presumiendo así de disentir de la Sede apostólica ${ }^{10}$. Tal conflicto no hubiera tenido sentido si se tratara de los "mozárabes antiguos" de Toledo a quienes se había permitido observar su rito en sus parroquias propias. Al contrario, cobra claro sentido si se considera que se trataba de los "mozárabes nuevos" llegados a mediados del siglo XII, quienes se habían incorporado a las parroquias latinas.

Sin embargo, este es el único caso de discriminación que se puede trazar contra los mozárabes toledanos. Frente a ello hay que poner en evidencia el carácter extraordinario del fuero de 1101, que dio Alfonso VI a todos los mozárabes de Toledo "caballeros y peones, que siempre he querido, dice, en esta ciudad, o que he traído de tierras extrangeras para poblar", otorgándoles, entre otras cosas, el ser juzgados entre ellos según el Fuero Juzgo ${ }^{11}$. Tal privilegio no tiene equivalente en Castilla ni en los otros reinos cristianos de la península. Por ejemplo, en Portugal, hubo un foral de los musulmanes de Lisboa y otras tres localidades, pero no de los mozárabes de la ciudad o de otras partes del reino ${ }^{12}$. La expresión del amor del soberano hacia los mozárabes de Toledo y hacia los traídos de Andalucía basta para desacreditar la opinión de autores que quieren ver en el término una intención peyorativa. Su derivación impecable del árabe musta 'rib (arabizante) basta para probar que fue adoptado por los cristianos arabohablantes como una reivindicación de su cultura árabe ${ }^{13 .}$

Por cierto, se puede notar, en la primera mitad del siglo XIII, la intención evidentemente malévola del arzobispo Rodrigo Jiménez de

${ }^{10}$ Rivera Recio, La Iglesia de Toledo, vol. 1, p. 209. Molénat, Campagnes et monts de Tolède, pp. 52-53.

${ }^{11}$ Muñoz y Romero, Colección de fueros municipales, pp. 360-362: “ad totos Muztarabes de Toleto, tam caballeros quam pedones (...) ut vos omnes, quos in hac urbe semper amavi et dilexi, seu de alienis terris ad populandum adduxi (...) et si inter eos ortum fuerit aliquod negotium de aliquo judicio, secundum sententias in libro judicum antiquitus constituto discutiatur (...)".

${ }^{12}$ Molénat, "Coïmbre, Tolède, Lisbonne: Chrétiens arabisés dans l'Hispanie de la 'Reconquête", comunicación al Coloquio Lisboa Medieval V, Lisboa, octubre 2017, en vías de publicación.

${ }^{13}$ Dominique Urvoy demostró que el árabe musta 'rib no fue utilizado por los autores musulmanes de al-Andalus como designación de los cristianos del país, aunque fue usado en Oriente por los árabes primeramente cristianos y luego convertidos al islam, que exaltaron así su arabidad. Vemos pues en la palabra "mozárabe" una reivindicación por parte de los mozárabes peninsulares de su propia arabización ("Les aspects symboliques du vocable 'Mozarabes', essai de réinterprétation"). 
Rada, cuando quiere explicar el término "mozárabe" por el latín "mixti arabes" (mezclados con los árabes): "et isti dicti sunt mixti Arabes, eo quod mixti Arabibus convivebant"14, mostrando además así su ignorancia de la lengua árabe, ocultada en su utilización de las crónicas árabes merced a la ayuda que pudieron ofrecerle los clérigos toledanos de origen mozárabe, todavía arabófonos en esa época.

A pesar de ello, la integración de los mozárabes toledanos en la mayoría cristiana del reino de Castilla parece que se realizó sin grandes problemas. Por una parte, la impronta lingüística árabe tuvo que borrarse poco a poco durante el siglo XIII, sin duda a consecuencia de la llegada de nuevos inmigrantes procedentes del norte, "francos" de más allá de los Pirineos y Castellano-Leoneses, permitiendo el cambio brusco del árabe hacia el castellano en la documentación urbana, en el momento de la transición del siglo XIII al XIV, sin que haya huella de un texto legislativo al respecto. Por otra parte, las élites mozárabes se integran en la élite del reino, los clérigos en la jerarquía eclesiástica, ocupando incluso la sede arzobispal varias veces entre la segunda mitad del XIII y la primera mitad del siglo siguiente, cuando los caballeros urbanos se integran en la nobleza del reino, llegando algunos de ellos a la primera fila de la "nobleza nueva" después de la llamada "revolución trastámara".

\section{Los musulmanes o "mudéjares"}

Parece que los musulmanes estuvieron casi del todo ausentes de la ciudad $^{15}$, y aún más de las zonas rurales circundantes ${ }^{16}$, durante más o menos un siglo y medio después del 1085. La teoría según la cual los musulmanes toledanos se habrían convertido al cristianismo para que-

${ }^{14}$ De Rebus Hispaniae, Libro III, cap. 22. J. Fernández Valverde traduce: "y a éstos se les dio el nombre de 'mozárabes', porque vivían mezclados con los árabes" (Jiménez de Rada. Historia de los Hechos de España, p. 152).

${ }^{15}$ Únicamente se han podido encontrar en la ciudad, para periodos anteriores a 1230, algunas personas indudablemente musulmanas, que llevan, por por ejemplo, el nombre de Muhammad (Campagnes et monts de Tolède, pp. 32-34).

${ }^{16}$ Un Sarracenus único figura mencionado, con su casa en el campo: "domos sarraceni qui dicitur Abdulla”, en 1193, en Manzil 'Ubayd Allāh, toponimo conservado en el actual despoblado de Mazarabea, cercano de la ciudad (Hernández, Los Cartularios de Toledo, $\left.n^{\circ} 248\right)$. 
darse cuando se produjo la entrada de Alfonso VI, transformándose así en los "mozárabes" de los documentos toledanos ${ }^{17}$, no se basa realmente en ningún argumento serio. Todo permite pensar que los musulmanes toledanos se habían marchado masivamente ya antes de mayo de 1085 , o poco después de la entrada en la ciudad de los cristianos del norte. Resultaría difícil pensar que hubiesen podido quedarse dentro de la ciudad cuando los almorávides acampaban a pocos kilómetros de los muros de Toledo.

El hecho de que se mencione una pequeña mezquita de barrio que tomaron los cristianos en $1159^{18}$, e incluso, que sea atestiguada en los años finales del siglo XII otra pequeña mezquita ${ }^{19}$, que seguirá funcionando en el centro de la ciudad hasta 1502 , y que se conoce como "la mezquita de las Tornerías", no contradice forzosamente la ausencia de un número sustancial de musulmanes libres (mudéjares) en aquellas fechas del siglo XII, pues se puede concebir que los cristianos toledanos hubiesen permitido a sus cautivos musulmanes, tomados en las algaradas efectuadas en el sur peninsular, cumplir con sus deberes religiosos, en particular la plegaría colectiva del viernes (la șalät), en lugares de culto propios.

Es probable que las cosas cambiaran durante la primera mitad del siglo XIII, con el gran avance de la conquista cristiana, la supuesta Reconquista, hacia el sur islámico de la península, después de las Navas de Tolosa (1212), y sobre todo de la toma de Córdoba en 1236, y de la de Sevilla en 1248. Tales éxitos cristianos tuvieron que arrastrar al cautiverio a miles de musulmanes de la Andalucía del Guadalquivir ${ }^{20}$, quienes fueron traídos hacia el norte por sus vencedores, y, por lo menos algunos de ellos, compraron su rescate por medio de su trabajo ${ }^{21}$, o fue-

\footnotetext{
${ }^{17}$ María Jesús Rubiera Mata, "Les premiers Mores convertis".

18 "Prisieron christianos la eglesia de S. Salvador de moros en dia de S. Juan Bautista, Era MCXCVII" (Anales Toledanos I, ed. Julio Porres, p. 134).

${ }^{19}$ González Palencia, Los Mozárabes de Toledo, doc. 904, con fecha de 1190: se menciona un mesón situado encima de los cambiadores, en el barrio de los Francos (rabad alIfranŷ), cerca de la mezquita de los musulmanes. En árabe masŷid al-muslimīn, y la nota al dorso en castellano "en barrio de Francos, sobre las tiendas de la Camia, cerca la Mezquita". Ambas expresiones implican que era el único lugar de culto islámico en aquel momento

${ }^{20}$ Por ejemplo, ya en 1212, después de la Navas de Tolosa, todos los habitantes de Úbeda fueron reducidos a esclavitud, en número de 60.000, y repartidos entre los combatientes (Jiménez de Rada, Historia de Rebus Hispanie, VIII, 12, trad. J. Fernández Valverde, p. 325; González, El reino de Castilla, vol. 1, p. 1059; Molénat, "Ubbadha".

${ }^{21}$ Molénat, "Mudéjars, captifs et affranchis".
} 
ron rescatados por parientes o amigos. Pero, incluso para aquellos así liberados, el regreso hacia la morada del islam (la dār al-islām) suponía muchos peligros, como el de ser nuevamente capturados por "descaminados", con riesgo de pena de muerte. Frente a tales peligros, quedarse en medio de los cristianos, en la tierra de infidelidad, podía constituir un mal menor, a pesar de la obligación coránica de emigrar ( hiŷra), cuya realización los sabios musulmanes, los ulemas, encontraron, hasta fines del siglo XV, justificaciones para retrasar, sin ponerla teóricamente en cuestión, claro está22.

Así pudo constituirse, en el corazón de la ciudad cristiana, un núcleo de musulmanes "mudéjares", posiblemente agrupados, en un primer momento ${ }^{23}$, en un barrio, una morería, situada alrededor de la pequeña mezquita del centro urbano. Es lo que hacen pensar dos textos árabes andalusíes cuando hablan de dos sabios musulmanes, de los cuales uno era nieto por línea materna del gran-cadí de Córdoba que se suele llamar en Europa Averroes (Ibn Rušd), quienes, capturados y rescatados, eligieron quedarse en Toledo para enseñar a sus correligionarios en el barrio de los musulmanes (fi rabad al-musliminn) ${ }^{24}$.

Durante el siglo XIV, a pesar del período de disturbios que afectan a la ciudad, como a los demás centros urbanos de la Corona de Castilla, los mudéjares toledanos no parecen padecer sus consecuencias, a diferencia, como se verá, de los judíos. Incluso toman parte, al menos, en algunos de los movimientos contra ellos ${ }^{25}$. No solo el reinado del rey Cruel, supuesto maurófilo, debió ser favorable a los moros de Toledo, sino que el favor real continuó con el medio-hermano, sucesor y homicida del precedente, Enrique de Trastámara. De hecho, fue en aquella época cuando se concretó la función del alcalde mayor de los moros de Castilla, ya prevista un siglo antes, sin ese nombre, por Alfonso X,

${ }^{22}$ Molénat, "Le problème de la permanence des musulmans".

${ }^{23}$ Hay que decir: "en un primer momento", porque en el período ulterior de los siglos XIV y XV, los mudéjares toledanos no aparecen agrupados, ni desde el punto de vista del lugar de residencia, ni en lo que toca al sitio de trabajo (Molénat, "Les musulmans dans l'espace urbain tolédan").

${ }^{24}$ Guichard y Molénat, "Dans al-Andalus, les ulémas face aux chrétiens".

${ }^{25}$ En 1355, el rey Pedro I excluye del perdón concedido a los toledanos que se habían levantado con él a "los moros de Toledo contra quien fuer fallado que fisieron algunos maleficios contra los mios judios en la mi juderia de Toledo a la sason que yo entre en Toledo" (Baer, Die Juden im christlichen Spanien, 1a. parte, Urkunden und Regesten, vol. 2, $\mathrm{n}^{\circ}$ 190. León Tello, Judios de Toledo, vol. 1, n²9, p. 409. Molénat, Campagnes et monts de Tolède, p. 302). 
pero cuyo titular no se conoce hasta los años 1370. Tal función será concedida con regularidad a un musulmán toledano durante el siglo siguiente, aun cuando el nombre parezca hacer alusión a una procedencia del reino de Granada ${ }^{26}$.

Sin embargo, se ve también que Enrique de Trastámara hizo a una mora toledana la donación verdaderamente real de las 84 tiendas del mercado del Alcaná, situado en el corazón comercial y religioso de la ciudad del Tajo, sobre el cual, a finales del siglo XIV, se edificó el claustro de la catedral. La sucesión de aquella musulmana dio lugar, en el contexto de la construcción del claustro, a un pleito del que, por desgracias, solamente se han encontrado algunas piezas hasta el momento ${ }^{27}$. Concretamente, no se dispone del documento (o de la copia) de la donación inicial del soberano a la mora Fátima. Al menos, resulta claro que dos hijas de la beneficiaria eran cristianas y casadas con cristianos, situación que causó el pleito sobre la sucesión, ya que los cristianos no podían ser herederos de musulmanes ni al revés; otra hija, musulmana, estaba casada con un personaje que conocemos por otra fuente con un nombre árabe completo, y quien será, en los primeros años del siglo XV, alcalde mayor de los moros de Castilla ${ }^{28}$. El asunto aporta prueba, o más bien confirmación, de varias cosas, que ya se podían intuir: en primer lugar, la existencia de una élite de la comunidad musulmana de Toledo, cercana al poder real, de cuyo favor se benefició. De esta forma se confirma y amplía lo que se podía percibir a partir de la documentación del siglo $\mathrm{XV}^{29}$. Se puede incluso llegar a pensar, considerando la amplitud de la donación de la que se benefició la mora Fátima, comparada con las del siglo posterior, que, en tiempos de Pedro I y Enrique II la situación de algunos, al menos, de los moros toledanos del siglo XIV era todavía más holgada que la que gozaron sus sucesores en los tiempos de Juan II y Enrique IV. Otro elemento que se pone en evidencia, probablemente relacionado con el anterior, es la procedencia de algunos miembros de tal élite mudéjar, la cual atestigua la nisba (ad-

${ }^{26}$ Molénat, "Alcaldes et alcaldes mayores de moros".

${ }^{27}$ Narciso de Estenaga, en su artículo: "Condición social de los mudéjares en Toledo durante la Edad Media", utilizó algunos documentos del archivo catedralicio de Toledo, sin dar referencias concretas. J.-P. Molénat y Jean Passini localizaron parte de tales documentos, que confirman afirmaciones de Estenaga que podrían parecer sorprendentes.

${ }^{28}$ Molénat, "Les noms des mudéjars revisités à partir de Tolède et de Lisbonne"; "Les noms des mudéjars revisités à partir de Tolède et du Portugal".

${ }^{29}$ Molénat, "L'élite mudéjare"; "Privilégiées ou poursuivies". 
jectivo de relación) que traen ellos, como don Abdalla el Rondí, primer alcalde mayor de los moros de Castilla nominalmente conocido, probablemente ya difunto en $1379^{30}$, y que parece proceder de la ciudad de Ronda, todavía entonces posesión nazarí, posiblemente llegado a Toledo en el contexto de las buenas relaciones existentes entre Pedro el Cruel y Muhammad V de Granada ${ }^{31}$.

Un tercer elemento interesante que evidencia el pleito sobre las tiendas del Alcaná es la tendencia que manifiestan algunos de los moros de Toledo de fines del siglo XIV a la conversión al cristianismo. La tendencia es evidente en la élite, con dos de las tres hijas de la mora Fátima llevando nombres cristianos y casadas con cristianos, pero se puede encontrar un caso similar en el común de los musulmanes de la ciudad: entre los testigos llamados para declarar en el pleito del Alcaná figura un tal Juan García, hijo de Maestre Hamete, carpintero, quien dice que cuando murió su madre, doña Mariem, no heredó nada, porque era cristiano, y heredaron sus hermanos, que seguían siendo musulmanes ${ }^{32}$.

A pesar de esto la comunidad musulmana de Toledo sigue en pleno vigor durante todo el siglo XV. Tal vigor se manifiesta, a altura de la segunda década del siglo, en las actas de una cofradía islámica de la ciudad, cuya publicación reciente ha revelado aspectos de gran interés ${ }^{33}$. En primer lugar, destaca el manejo perfecto del idioma árabe por los escribas de la cofradía, en una época en que, por lo común, se afirma el olvido de la lengua por los mudéjares de Castilla, apoyándose en la frase de Ice de Gebir, el muftí de Segovia de los años 1460, quien deplora la pérdida de las escuelas del árabe por los moros de Castilla ${ }^{34}$. Pero la práctica y la enseñanza de la lengua pudieron mantenerse de manera diferente a la de las escuelas, por ejemplo, en el medio familiar.

${ }^{30}$ Molénat, “Alcaldes et alcaldes mayores de moros", específicamente p. 151.

${ }^{31}$ Se ha formulado la hipótesis según la cual la proposición que hizo Pedro el Cruel a Ibn Jaldūn de restituirle las tierras de sus antecesores para que se quedase en sus estados, respondía al deseo del monarca de encontrar una persona que pudiera ocupar el puesto de alcalde mayor de los moros de Castilla (Molénat, "Ibn Jaldún ante Pedro I de Castilla").

32 "quando donna Mariem madre deste testigo murio que este testigo que non heredo ninguna cosa de lo que su madre dexo por quanto era xpiano et que lo heredo los otros sus hermanos que ffincaron moros" (Archivo del Cabildo Catedralicio de Toledo, E.6.A.4.1, suplemento $146, \mathrm{f}^{\circ} 64 \mathrm{r}^{\circ}$; corrigiendo el ffinaron del texto en ffincaron).

${ }^{33}$ Echevarría y Mayor, "Las actas de reunión".

34 "Y por que los moros de Castilla (...) han descaeçido de sus riquezas y an perdido las escuelas del arábigo" (Suma de los principales mandamientos y devedamientos de la Ley y Çunna, p. 248. 
El segundo aspecto importante de tales actas es que el sistema onomástico complejo del árabe, que desaparece por completo para los mudéjares en beneficio de un sistema más simple, las más de las veces binario (nombre personal más oficio) en los documentos castellanos ajenos a la comunidad, está mucho mejor preservado en árabe, al menos para los miembros de la élite mudéjar, para quienes es a veces posible reconstruir un nombre árabe completo.

En todo caso, y aun para los mudéjares del común, y en la documentación en lengua castellana, el apego a la religión islámica se atestigua, durante todo el siglo $\mathrm{XV}$, por la elección muy mayoritaria, tanto para los varones como para las mujeres, de nombres de persona que hacen referencia a Muhammad y a los primeros tiempos del islam, aun cuando había otras opciones disponibles que respetaban la obligación legal de llevar nombres diferentes a los de los cristianos ${ }^{35}$.

La localización de los musulmanes en la ciudad queda, durante todo el siglo XV, marcada por la ausencia de un barrio específico, una dispersión en medio de los cristianos, tanto en lo que se refiere a los lugares de residencia, como a los emplazamientos profesionales, con una excepción notable, la de los hornos de alfareros, que tienen los moros en parte del arrabal de la ciudad. El oficio de alfarero es, igualmente, el único en que se manifiesta una especialización de los musulmanes, que va creciendo en el último cuarto del siglo $\mathrm{XV}^{36}$. Hay una relación clara entre los dos fenómenos, que atestiguan de un apartheid que aumenta hasta el final del siglo, cuando se aproxima al edicto de 1502 marcando el fin de la existencia mudéjar, sin que nunca lleguen a concretarse en la ciudad las medidas segregacionistas promulgadas en Castilla desde principios del siglo $\mathrm{XV}^{37}$, reafirmadas y reforzadas por los Reyes Católicos desde los albores de su reinado ${ }^{38}$.

${ }^{35} \mathrm{La}$ opción de nombres evidentemente árabes, pero sin connotación religiosa, es más visible para las mujeres que para los hombres (Molénat, “'A'ixa, Fāṭima, Maryam”).

${ }^{36}$ Molénat, "Les musulmans dans l'espace urbain tolédan"; "Los musulmanes y agua en Toledo".

${ }^{37}$ Ley promulgada en 1412 por la regente Catalina de Lancaster, cuyo primer artículo estipula que los musulmanes y judíos deben vivir en lugares separados de los cristianos (Fernández y González, Estado social y político, doc. 77, p. 400. Carrasco Manchado, De la convivencia a la exclusión, doc. 53, p. 179).

${ }^{38}$ Molénat, "En los últimos años del siglo XV"; "Des 'vieux mudéjars' aux morisques de Castille".

Al-Qanțara XL 2, 2019, pp. 385-405 ISSN 0211-3589 doi: https//doi.org/10.3989/alqantara.2019.012 


\section{Los judíos y judeoconversos}

Los judíos ya estaban presentes en la ciudad en los tiempos del reino visigodo de Toledo, y se conoce bien la persecución cruel de la que fueron entonces víctimas ${ }^{39}$. Lo que queda menos claro es el papel que desempeñaron en la conquista islámica de la península, y en particular de la de Toledo ${ }^{40}$. Aunque la mayoría de las crónicas árabes andalusíes mencionan que en Toledo, al igual que en otros lugares de la península, la ciudad ya conquistada fue entregada a los judíos por falta de contingentes suficientes para guardarla, hay que ver en tal noticia más bien la expresión de la buena armonía que existía, o se suponía que existía, en al-Andalus, entre musulmanes y judíos, y que no figura en las fuentes cristianas más antiguas, notablemente la Crónica del $754^{41}$. El relato adquiere tonalidad inversa con el cronista leonés Lucas de Tuy, cuando este atribuye la pérdida de la ciudad de los reyes a una conspiración y traición por parte de los judíos toledanos ${ }^{42}$. Pero en el momento en que escribe el Tudense, el antisemitismo (o más bien el antijudaísmo) ya estaba difundido en los reinos cristianos del norte peninsular y se había manifestado en Toledo con el primer motín dirigido contra los judíos posteriormente a 1085, registrado con fecha del 14 de agosto de 1108 , posiblemente a consecuencia del desastre de la batalla de Uclés, en la que murió el infante don Sancho, único heredero varón de Alfonso VI ${ }^{43}$.

En este contexto, toma significación especial el episodio de 1212, donde se ve a los cruzados recién llegados de más allá de los Pirineos para participar en la expedición de las Navas de Tolosa (en la que, por otro lado, no van a participar de forma efectiva), asaltar la judería de Toledo, que será, al contrario, defendida por los caballeros toledanos ${ }^{44}$.

${ }^{39}$ Bronisch, Die Judengesetzgebung.

${ }^{40}$ Sobre los relatos de la conquista de Toledo por los arabo-bereberes, y el papel que tomaron en ella los judíos, Molénat, "El relato de la conquista de Toledo", artículo escrito para un volumen en Homenaje a D. Ramón Gonzálvez Ruiz (Academia de Bellas Artes y Ciencias Históricas de Toledo), en vías de publicación.

${ }^{41}$ López Pereira (ed.), Crónica mozárabe de 754.

${ }^{42}$ Lucae Tudensis Chronicon Mundi, Liber III, p. 222.

${ }^{43}$ Anales Toledanos Primeros, vol. 23, p. 373: "Mataron al infant D. Sancho e al conde D. García cerca de Uclés, III día kal. de Junio, era M CXLVI. Mataron a los judíos de Toledo, día de domingo, vispera de Santa María de Agosto, eera MCXLVI".

${ }^{44}$ Anales Toledanos I y II, p. 172: "movieronse los dultra puertos e vinieron a Toledo en dia de Cinquesma, e volvieron todo Toledo, e mataron de los judios dellos muchos, e 
¿Cómo podemos entender tal episodio, contradictorio con el de 1108 , y con los que van a jalonar los dos siglos siguientes? Nos atrevemos a sugerir que la "mozarabización" de Toledo, más avanzada a principios del siglo XIII de lo que estaba cien años antes, con la llegada de los mozárabes del sur a mediados del XII, puede ofrecer una clave interpretativa: los cristianos arabizados estaban más dispuestos a aceptar la coexistencia entre religiones, a que habían estado acostumbrados durante el dominio del islam, con el régimen de la dimma, que los recién llegados de más allá de los Pirineos.

Queda claro que durante el resto del siglo XIII, y los dos siglos siguientes, la impronta mozárabe de Toledo no podía sino declinar, por el hecho de la llegada de colonos venidos del norte, a pesar de que accedieron a la dignidad arzobispal toledana varios prelados de origen mozárabe, para por fin borrarse del todo en el XV. Pero durante gran parte de los dos siglos finales de la Edad Media, la coyuntura de crisis demográfica y económica y de disturbios, llegando a una guerra civil ${ }^{45}$, pudo sin duda todavía con más fuerza suscitar la hostilidad violenta del pequeño pueblo toledano, cristiano pero también musulmán, contra la minoría judía de la ciudad.

Se registran en Toledo, por tanto, movimientos dirigidos contra los judíos, y después los judeo-conversos, en 1355, 1391, 1449 y 1467. El primero de ellos se sitúa en el contexto del reinado de Pedro el Cruel, y la revuelta de dos hermanastros bastardos del rey, que entraron en la ciudad y mataron a los judíos de un barrio separado de la judería mayor. Pero hubo otra vez caballeros urbanos, partidarios del rey, que ejercieron la defensa de los judíos ${ }^{46}$, cuando queda atestiguado que los mudé-

armaronse los caballeros de Toledo e defendieron a los judíos”. Óscar López Gómez, sitúa en fecha sin precisar, entre febrero y junio de 1212, la masacre de los judíos por las tropas extranjeras, y supone el apoyo del rey y del arzobispo a la defensa de los judíos que organizaron los notables urbanos ("La ciudad de la cruzada, Toledo 1212", específicamente, p. 412). M. Alvira Cabrer piensa igualmente que el arzobispo pudo instigar la milicia toledana a intervenir para poner fin a los ataques contra los judíos, pero añade que no hay prueba de ello (Las Navas de Tolosa 1212, p. 138).

${ }^{45}$ Molénat, "De la crise rurale à l'expansion", en Campagnes et monts de Tolède, tercera parte: "Crise et mutations des campagnes aux XIVe et XVe siècles", cap. primero, pp. 287-317.

${ }^{46}$ López de Ayala, Crónica del Rey don Pedro, vol. 1, p. 204, año 6, cap. 7. En la transmisión del texto del Canciller, hubo confusión entre los nombres del Alcaná y de la Alacaba, este último designando el sector separado de la judería mayor y no protegido por un muro como esta (Molénat, "Quartiers et communautés à Tolède", específicamente p. 172). 
jares tomaron parte en los actos violentos ${ }^{47}$. En 1391, el movimiento, salido de Andalucía, en un contexto de crisis en el reino, tanto política, por la minoría de edad del rey, como económica, con una tentativa de reforzamiento monetario, iniciado por el arcediano de Écija Fernán Martínez, llega no solo a Toledo, sino también a las zonas rurales circundantes, cuyos habitantes toman parte activa en el saqueo de la judería $^{48}$. Según algunos autores, los musulmanes participaron en esos disturbios $^{49}$. Se sabe que los acontecimientos de 1391 provocaron, tanto en Toledo como en otros lugares de la península, un importante movimiento de conversión al cristianismo por parte de los judíos, cuya sinceridad quedó evidentemente en duda muchas veces.

Por supuesto, la conversión, fuese sincera o ficticia, no terminó con la hostilidad hacia los nuevamente convertidos. Todo lo contrario, la hostilidad se vio acrecida por la convergencia de los fenómenos característicos del siglo XV castellano en general y toledano en particular. Por un lado, la expansión económica que sucedió a las crisis del siglo XIV dio lugar a la constitución de una importante capa social "burguesa" que se dedicó en primer lugar al comercio, pero también al manejo del dinero, en particular con el arrendamiento de las rentas reales ${ }^{50}$, y que se reclutaba en gran parte entre los nuevos convertidos. Por otro lado, la desaparición de la barrera legal religiosa permitió el acceso a funciones hasta el momento prohibidas, y la penetración hasta las filas de la aristocracia dominante, por medio de las uniones matrimoniales ${ }^{51}$.

En lo que se refiere a la revuelta de 1449 en Toledo, no hay duda de que los actos de violencia afectaron en primer lugar a la élite judeoconversa. La insurrección se desarrolló a partir de un movimiento anti-fiscal dirigido contra el recaudador de impuestos converso, Alonso

\footnotetext{
${ }^{47}$ Molénat, Campagnes et monts de Tolède, p. 302, nota 99. León Tello, Judios de Toledo, vol. 1, p. 409 , doc. 29.

${ }^{48}$ León Tello, Judios de Toledo, vol. 1, pp. 174-181, y p. 440, doc. 440. Molénat, Campagnes et monts de Tolède, p. 301.

${ }^{49}$ Baer, Historia de los judíos, vol. 2, p. 384, sin referencia.

${ }^{50}$ Ortego Rico, Poder financiero y gestión tributaria en Castilla, en particular el apéndice $\mathrm{V}$ que da el catálogo prosopográfico de todos los hacendistas mencionados en la obra.

${ }^{51}$ Esos fenómenos se han estudiado, en el caso toledano, en el capítulo octavo de la tercera parte de Molénat, Campagnes et monts de Tolède, pp. 555-609: "Les transformations de l'économie et de la société urbaine au XVe siècle. L'émergence d'une bourgeoisie et son intervention dans les problèmes agraires". Valdría la pena seguir con la investigación, particularmente a nivel prosopográfico.
} 
Cota, como un ataque contra los conversos y los ricos, para dirigirse en último lugar contra el privado real, Álvaro de Luna, el soberano, y finalmente el papa, acusados de connivencia con los "falsos cristianos". Ello dio lugar a la redacción del texto conocido como "la sentencia-estatuto de Pero Sarmiento", que declaró a los "confesos" privados de todo oficio en Toledo y su jurisdicción, y otro designado como "el memorial de Marcos García de Mora contra los conversos" 52 . Ambos textos fueron en su momento condenados por las autoridades civiles y religiosas, pero acabaron con el tiempo siendo el primer esbozo de los conocidos estatutos de limpieza de sangre de la España moderna ${ }^{53}$.

Los disturbios de 1467 en Toledo vieron otra vez enfrentarse a los dos partidos de los llamados cristianos viejos y los conversos, cada uno de ellos apoyado por una facción de la nobleza urbana ${ }^{54}$.

\section{Conclusión}

A pesar de que terminamos evocando episodios de violencia, no hay duda de que no son dominantes, y no prevalecen sobre la coexistencia más o menos pacífica entre las comunidades religiosas, excepto posiblemente en el epílogo final de la larga historia de la que he esbozado aquí un rápido repaso.

En primer lugar, entre cristianos latinos y mozárabes, no hubo, a pesar de lo que algunos autores pretenden ${ }^{55}$, oposición abierta ni persecución de estos últimos. El mismo prelado que denigraba a los mozárabes calificándolos de "mezclados con los árabes" no tenía escrúpulos en emplearlos para la redacción de sus obras. Más aun, consiguieron en lo que siguió de siglo alcanzar la cima de la jerarquía urbana, con la sede arzobispal ocupada por varios de sus representantes sucesivos. Sus líderes civiles y militares se integraron en la nobleza más alta del reino, al precio, es verdad, del olvido de sus orígenes. Probablemente fue la inteligencia del reconquistador de Toledo, Alfonso

\footnotetext{
${ }^{52}$ Benito Ruano, Toledo en el siglo XV, pp. 48, 93, y otros trabajos del mismo autor.

${ }^{53}$ Albert Sicroff, Les controverses. González Rolán y Saquero Suárez-Somonte, De la Sentencia-Statuto.

${ }^{54} \mathrm{El}$ análisis más reciente de los acontecimientos de 1467 en Toledo se encuentra en López Gómez, Los Reyes Católicos y la pacificación de Toledo, específicamente pp. 5471: "1467, el último ataque colectivo a los judeoconversos".

${ }^{55}$ Pastor de Togneri, Del Islam al Cristianismo.
} 
VI, lo que permitió el éxito de tal integración pacifica de los mozárabes, no solo de los que habían permanecido en Toledo en tiempos del islam, sino también de los llegados de otras partes de la península.

En lo que se refiere a los musulmanes, la historia es más compleja, incluso contradictoria. Por un lado, su ausencia es muy verosímil durante el siglo y medio que siguió a la entrada de Alfonso VI en la ciudad. Sin embargo, después de los años 1230, se impone la evidencia de la presencia mudéjar, posiblemente por el hecho de la dificultad y los peligros del regreso hacia la morada del islam, pero también porque, al fin y al cabo, el estatuto de la dimma invertida que se les había otorgado permitía una vida aceptable, nunca expuesta a los furores de la población mayoritaria. Los mudéjares toledanos fueron, sin duda, en su mayoría, gentes más bien humildes, pero había entre ellos algunos que gozaban del favor real, por los servicios que podían ofrecer al soberano cristiano, del que recibían retribución, como por ejemplo las mujeres que ayudaban al nacimiento de niños reales, o los hombres que dirigían a sus correligionarios en la obediencia al rey cristiano o que cobraban de ellos las contribuciones pesadas que se les exigían, o ejercían sus talentos médicos.

Una cosa cierta es que sobre los mudéjares toledanos nunca se desencadenó una violencia comparable a la que experimentaron los $s a-$ rraïns de Valencia ${ }^{56}$, o incluso los movimientos que, en la Meseta castellana del norte, precedieron el edicto de $1502^{57}$. La diferencia con la situación valenciana puede explicarse por la posición mucho más minoritaria de los mudéjares toledanos, haciendo que ellos no aparecieran como contrincantes de los cristianos. El contraste con el norte castellano puede corresponder a un hábito de convivencia mucho más enraizado, que se manifiesta también en la ausencia de un barrio específico de los musulmanes toledanos.

Quedaría por explicar la recurrencia de los movimientos dirigidos contra judíos y judeoconversos, en contraste con la convivencia pacífica de que gozaron los mudéjares toledanos. La hostilidad religiosa contra los judíos no basta, evidentemente, para la explicación, pues se hubiera dirigido con más motivos contra los musulmanes, cuya fe cons-

${ }^{56}$ Barceló Torres, "La morería de Valencia". José Hinojosa Montalvo, "Cristianos contra musulmanes".

${ }^{57}$ Molénat, "En los últimos años del siglo XV"; "Des "vieux mudéjars " aux morisques de Castille". 
tituyó, durante todo el período y en toda la península, el desafío más grave a la religión cristiana, y la conversión al cristianismo no era suficiente, como se ha visto, para dar fin a ella. Queda claro, que, al menos para los siglos XIV y XV, la base verdadera de los movimientos populares cristianos (y musulmanes) contra los judíos y judeoconversos se encontraba en su papel de manejadores de dinero y perceptores de impuestos, agravado por su ascenso social después de la conversión. En resumen, una oposición económica y social más que otra cosa.

\section{Bibliografía}

Alvira Cabrer, Martín, Las Navas de Tolosa 1212. Idea, liturgia y memoria de la batalla, Madrid, Silex, 2012.

Baer, Yitzhak, Historia de los judios en la España cristiana, José Luis Lacave (trad.), 2 vol., Madrid, Altalena, 1981.

Barceló Torres, María del Carmen, "La morería de Valencia en el reinado de Juan II", Saitabí 30 (1980), pp. 49-71.

Barrio Barrio, Juan Antonio, "Los judeoconversos hispanos y su problemática inserción en la sociedad cristiana urbana peninsular", en Maria Filomena Lopes de Barros y José Ramón Hinojosa Montalvo (eds.), Minorias étnico-religiosas na Península Ibérica. Periodo medieval e moderno, Evora, Ediçoes Colibri Publicaçôes do Cidehus - Universidade de Evora - Universidade de Alicante, 2008, pp. 239-258.

Benito Ruano, Eloy, Toledo en el siglo XV. Vida política, Madrid, CSIC, 1961.

Bronisch, Alexander Pierre, Die Judengesetzgebung im katholischen Westgotenreich von Toledo, Hannover, Verlag Hahnsche Buchhandlung, 2005, Forschungen zur Geschichte der Juden, 17.

Carrasco Manchado, Ana Isabel, De la convivencia a la exclusión. Imágenes legislativas de mudéjares y moriscos. SigloXIII-XVII, Madrid, Silex, 2012.

Chamocho Cantudo, Miguel Ángel, Los fueros del reino de Toledo y Castilla la Nueva, Madrid, Agencia Estatal Boletín Oficial del Estado, 2017.

Echevarría Arsuaga, Ana, "Better Muslim or Jew? The Controversy Around Conversion across Minorities in Fifteenth-Century Castile", Medieval Encounters, 24, 1-3 (2018), pp. 62-78.

Echevarría Arsuaga, Ana (ed.), Biografías mudéjares o la experiencia de ser minoría: biografías islámicas en la España cristiana, Madrid, CSIC, 2008, Estudios onomástico-biográficos de al-Andalus, 15.

Echevarría, Ana y Mayor, Rafael, "Las actas de reunión de una cofradía islámica de Toledo, una fuente árabe para el estudio de los mudéjares castellanos", Boletín de la Real Academia de la Historia, 207, 3 (2010), pp. 257-293. 
Estenaga, Narciso de, "Condición social de los mudéjares en Toledo durante la Edad Media”, Boletín de la Real Academia de Bellas Artes y Ciencias Históricas de Toledo, 18-19 (1924), pp. 5-27.

Fernández Conde, Francisco Javier, "Política religiosa de Alfonso VI", en Alfonso VI y su legado. Actas del Congreso Internacional IX Centenario de Alfonso VI (1109-2009), León, Diputación de León - Instituto Leonés de Cultura, 2012, pp. 37-62.

Fernández y González, Francisco Estado social y político de los mudéjares de Castilla, reed. con prólogo Mercedes García-Arenal, Madrid, Hiperión, 1985 ( $1^{\text {a }}$ ed. Madrid, 1866).

González, Julio, El reino de Castilla en tiempo de Alfonso VIII, Madrid, CSIC, 1960, 3 vol.

González, Julio, Repoblación de Castilla la Nueva, Madrid, Universidad Complutense, 1975, 2 vol.

González Rolán, Tomás y Saquero Suárez-Somonte, Pilar, De la Sentencia-Statuto de Pero Sarmiento a la Instrucción del Relator. Estudio introductorio, edición crítica y notas de los textos contrarios y favorables a los judeoconversos a raíz de la rebelión de Toledo de 1449, Madrid, Aben Ezra Ediciones, 2012.

Gonzálvez Ruiz, Ramón, “Toledo, último reducto del mundo mozárabe”, en Manuel González Jiménez y Juan del Río Martín (eds.), Los mozárabes. Una minoría olvidada, Sevilla, Fundación El Monte, 1997, pp. 47-86.

Guichard, Pierre, Molénat, Jean-Pierre, "Dans al-Andalus, les ulémas face aux chrétiens", en André Bazzana, Nicole Bériou y Pierre Guichard, (eds.), Averroès et l'averrö̈sme. Un itinéraire historique du Haut Atlas à Paris et à Padoue, Lyon, Presses Universitaires de Lyon, 2005, pp. 191-200.

Hinojosa Montalvo, José, "Cristianos contra musulmanes. La situación de los mudéjares", en José Ignacio De la Iglesia Duarte, (coord.), Conflictos sociales, políticos e intelectuales en la España de los siglos XIII-XV. XIV Semana de Estudios Medievales, Nájera, 2003, Logroño, Instituto de Estudios Riojanos, 2004, pp. 335-392.

Hinojosa Montalvo, José, “Los Judíos en la Corona de Aragón. La recuperación de la memoria histórica en torno a una minoría", en Maria Filomena Lopes de Barros y José Hinojosa Montalvo (eds.), Minorias étnico-religiosas na Península Ibérica. Periodo medieval e moderno, Evora, Ediçoes Colibri - Publicaçôes do Cidehus - Universidade de Evora - Universidade de Alicante, 2008, pp. 93-142.

Kadri, Alice, Moreno, Yolanda y Echevarría, Ana (eds.), Circulaciones mudéjares y moriscas. Redes de contacto y representaciones, Madrid, CSIC, 2018, Estudios árabes e islámicos. Monografías, 2.

León Tello, Pilar, Judios de Toledo, 2 vol., Madrid, CSIC, 1979.

López Gómez, Óscar, “La ciudad de la cruzada, Toledo 1212”, en Carlos Estepa Díez y María Antonia Carmona Ruiz (eds.), La Península Ibérica en tiempo 
de las Navas de Tolosa, Madrid, Sociedad Española de Estudios Medievales, 2013, pp. 399-416.

López Gómez, Óscar, Los Reyes Católicos y la pacificación de Toledo, Madrid, A. C. Castellum, 2008.

Molénat, Jean-Pierre, “'A'’ixa, Fāṭima, Maryam. Noms de femmes musulmanes en Castille et Portugal, XIIIe-XVe s.", en VIII Estudios de Frontera. Mujeres y Fronteras. Congreso Homenaje a doña Cristina Segura Graiño (Congreso celebrado en Alcalá la Real, 19 y 20 noviembre de 2010), Jaén, Diputación de Jaén, 2011, pp. 295-302.

Molénat, Jean-Pierre, "Alcaldes et alcaldes mayores de moros de Castille au XV siècle", en François Géal (ed.), Regards sur al-Andalus (VIII ${ }^{e}-X V^{E}$ siècle), Madrid-Paris, Casa de Velázquez-Éditions Rue d'Ulm, 2006, pp. 147-168.

Molénat Jean-Pierre, Campagnes et monts de Tolède du XII ${ }^{e}$ au XVe siècle, Madrid, Casa de Velázquez, 1997.

Molénat, Jean-Pierre, "L'élite mudéjare dans la péninsule Ibérique médiévale", en Filipe Themudo Barata (ed.), Elites e redes clientelares na Idade Média, Lisbonne, Ed. Colibri-CIDEHUS, 2001, pp. 45-53.

Molénat, Jean-Pierre, "En los últimos años del siglo XV: el fin de los 'mudéjares viejos' de Castilla”, en José Ángel García de Cortázar et al. (eds.), Fines de siglo y milenarismo en la historia, Valladolid, Instituto Universitario de Historia Simancas, 2000, pp. 31-56.

Molénat, Jean-Pierre, "Ibn Jaldún ante Pedro I de Castilla. El revés de un encuentro", en María Jesus Viguera Molins (ed.), Ibn Jaldún. El Mediterráneo en el siglo XIV. Auge y declive de los Imperios. Exposición en el Real Alcázar de Sevilla, Mayo-Septiembre 2006, Sevilla, El Legado Andalusí, 2006, pp. 164-169.

Molénat, Jean-Pierre, "Mudéjars, captifs et affranchis", en Louis Cardaillac (dir.), Tolède, XIIe-XIIIe. Musulmans, chrétiens et juifs. Le savoir et la tolérance, Paris, Autrement, 1991, pp. 112-124.

Molénat, Jean-Pierre, "Les musulmans dans l'espace urbain tolédan aux XIVe et $\mathrm{XV}$ siècles", Minorités et marginaux en France méridionale et dans la péninsule Ibérique (VII ${ }^{e}$ XVIII ${ }^{e}$ siècles). Actes du colloque de Pau, 27-29 mai 1984, Paris, CNRS, 1986, pp. 129-141.

Molénat, Jean-Pierre, "Los musulmanes y el agua en Toledo entre los siglos XII y XV", en Rebeca Rubio Rivera, Jean Passini y Ricardo Izquierdo Benito (eds.), El agua en Toledo y su entorno. Épocas romana y medieval, Cuenca, Ediciones de la Universidad de Castilla-La Mancha, 2018, pp. 236-242.

Molénat, Jean-Pierre, "Les noms des mudéjars revisités à partir de Tolède et de Lisbonne", En la España Medieval 35 (2012), pp. 75-98.

Molénat, Jean-Pierre, "Les noms des mudéjars revisités à partir de Tolède et du Portugal", en Christian Müller y Muriel Roiland-Rouabah (eds.), Les nondits du nom. Onomastique et documents en terres d'Islam. Mélanges offerts à Jacqueline Sublet, Damasco-Beirut, Presses de l'Ifpo, 2013, pp. 437-460. 
Molénat, Jean-Pierre, "Privilégiées ou poursuivies, quatre sages-femmes musulmanes dans la Castille du XVe siècle", en Cristina de la Puente (ed.), Identidades marginales, Madrid, CSIC, 2003, Estudios Onomástico-biográficos de al-Andalus, 13, pp. 413-430.

Molénat, Jean-Pierre, "Le problème de la permanence des musulmans dans les territoires conquis par les chrétiens, du point de vue de la Loi islamique", Arabica 48, 3 (2001), pp. 392-400.

Molénat, Jean-Pierre, "Quartiers et communautés à Tolède, $\mathrm{XII}$ - $-\mathrm{XV}$ ' siècles", En la España Medieval 12 (1989), pp. 163-189.

Molénat, Jean-Pierre, "Les relations des musulmans de Castille et du Portugal avec ceux de la dār al-islām, du XII ${ }^{\mathrm{e}}$ au XV $\mathrm{XV}^{\mathrm{e}}$ siècle", en Alice Kadri, Yolanda Moreno y Ana Echevarría (eds.), Circulaciones mudéjares y moriscas. Redes de contacto y representación, Madrid, CSIC, 2018, pp. 71-91.

Molénat, Jean-Pierre, "El relato de la conquista de Toledo por los musulmanes (711) según las crónicas árabes andalusíes y cristianas", artículo escrito para un volumen en Homenaje a D. Ramón Gonzálvez Ruiz (Academia de Bellas Artes y Ciencias Históricas de Toledo), en vías de publicación.

Molénat, Jean-Pierre, "Sur le rôle des Almohades dans la fin du christianisme local au Maghreb et en al-Andalus", Al-Qantara 18, 2 (1997), pp. 389-413.

Molénat, Jean-Pierre, “Ubbadha”, Encyclopédie de l'Islam, 2a ed., Leiden, Brill, 2002, vol. 10, pp. 824-826.

Molénat, Jean-Pierre, “Des 'vieux mudéjars' aux morisques de Castille (fin XVedébut XVI ${ }^{\mathrm{e}}$ siècle)", Sharq al-Andalus 20 (2011-2013), pp. 67-81.

Molénat, Jean-Pierre, "Y a-t-il eu des mozarabes à Tolède du VIII ${ }^{\mathrm{e}}$ au XI $\mathrm{XI}^{\mathrm{e}}$ siècle?", en Entre el Califato y la Taifa. Mil años del Cristo de la Luz. Actas del Congreso Internacional, Toledo, 1999, Toledo, Asociación de Amigos del Toledo Islámico, pp. 97-106.

Ortego Rico, Pablo, "Los mudéjares de Castilla y la migración a dār al-islām (ca. 1450-1502): ¿superioriadad del vínculo religioso sobre el de naturaleza?”, en Alice Kadri, Yolanda Moreno y Ana Echevarría (eds.), Circulaciones mudéjares y moriscas. Redes de contacto y representación, Madrid, CSIC, 2018, pp. 35-70.

Ortego Rico, Pablo, Poder financiero y gestión tributaria en Castilla. Los agentes fiscales en Toledo y su reino (1429-1504), Madrid, Instituto de Estudios Fiscales, 2015.

Pastor de Togneri, Reyna, Del Islam al Cristianismo. En la frontera de dos formaciones económico-sociales: Toledo, siglos XI-XIII, Barcelona, Ed. Península, 1975.

Rivera Recio, Juan Francisco, La Iglesia de Toledo en el siglo XII (1086-1208), Roma, Iglesia Nacional Española, 1966, vol. 1.

Rubiera Mata, María Jesús, "Les premiers Mores convertis ou les prémices de la tolérance”, en Louis Cardaillac (ed.), Tolède (XIIe-XIIIe), Paris, Autrement, 1991. 
Sicroff, Albert A, Les controverses des statuts de 'pureté de sang'en Espagne du $X V^{e}$ au XVII ${ }^{e}$ siècle, Toulouse, Privat, 1960. Traducción española: Los Estatutos de limpieza de sangre. Controversias entre los siglos XV y XVII, Madrid, Taurus, 1985.

Soyer, François, "The Massacre of the New Christians of Lisbon in 1506: A New Eyewitness Account”, Cadernos de Estudos Sefarditas 7 (2007), pp. 221-244.

Soyer, François, The Persecution of the Jews and Muslims of Portugal. King Manuel I and the End of Religious Tolerance (1496-7), Leiden, Brill, 2007. Traducción portuguesa: A Perseguição aos Judeus e Muçulmanos de Portugal - D. Manuel I e o Fim da Tolerância Religiosa (1496-1497), Lisboa, Edições 70, 2013.

Urvoy, Dominique, “Les aspects symboliques du vocable 'Mozarabes', essai de réinterprétation”, Studia Islamica 78 (1993), pp. 117-153.

\section{Fuentes}

Archivo del Cabildo Catedralicio de Toledo, E.6.A.4.1, suplemento 146.

Anales Toledanos I y II, Julio Porres (ed.), Toledo, Instituto Provincial de Investigaciones y Estudios Toledanos, 1993.

Anales Toledanos Primeros, E. Flórez (ed.), España Sagrada, vol. 23, Guadarrama, Ed. Revista Agustiniana, 2007 (original, Madrid, 1767).

Baer, Fritz, Die Juden im christlichen Spanien, $1^{\text {a }}$ parte, Urkunden und Regesten, Berlin, Schocken Verlag, 1929-1936. Reed. GB, 1970.

De Gebir, Içe, Suma de los principales mandamientos y devedamientos de la Ley y Çunna, en Tratados de legislación musulmana publicados por la Real Academia de la Historia, Madrid, Imprenta Real Academia de Historia, 1853, pp. 237-431. González Palencia, Angel (ed. y trad.), Los Mozárabes de Toledo en los siglos XII y XIII, Madrid, Instituto de Valencia de Don Juan, 1926-1930, 4 vol.

Hernández, Francisco Javier (ed.), Los Cartularios de Toledo, Madrid, Fundación Ramón Areces, 1985.

Jiménez de Rada, Rodrigo, De Rebus Hispaniae, Juan Fernández Valverde (ed.), Turnhout, Brepols, 1987.

Jiménez de Rada, Rodrigo, Historia de los Hechos de España, Juan Fernández Valverde (trad.), Madrid, Alianza, 1989.

López de Ayala, Pero, Crónica del Rey don Pedro y del Rey don Enrique, su hermano, hijos del rey don Alfonso Onceno, Germán Orduna (ed.), Buenos Aires, Secrit, 1994-1997, 2 vol.

López Pereira, Eduardo (estudio, ed. y trad.), Continuatio Isidoriana Hispana. Crónica mozárabe de 754, León, Centro de Estudios e Investigación "San Isidoro", 2009, Fuentes y Estudios de Historia Leonesa, 127. 
Lucas Tudensis Chronicon Mundi, Emma Falque (ed.), Turnhout, Brepols, 2003. Muñoz y Romero, Tomás (ed.), Colección de fueros municipales y cartas pueblas de los reinos de Castilla, León, Corona de Aragón y Navarra, Madrid, 1972 ( $1^{\mathrm{a}}$ ed. Madrid, 1847).

Recibido: 10/12/2019

Aceptado: 17/12/2019 